\title{
A Dose-Finding Study of Dexketoprofen in Patients Undergoing Laparoscopic Cholecystectomy: A Randomized Clinical Trial on Effects on the Analgesic Concentration of Oxycodone
}

\author{
Annika Piirainen ${ }^{1,2}$ - Hannu Kokki ${ }^{1,2} \cdot$ Satu Immonen ${ }^{2,3}$ - Matti Eskelinen ${ }^{4}$. \\ Merja R. Häkkinen $^{3} \cdot$ Heidi Hautajärvi ${ }^{5} \cdot$ Merja Kokki $^{1,2}$
}

Published online: 12 September 2015

(c) The Author(s) 2015. This article is published with open access at Springerlink.com

\begin{abstract}
Background Dexketoprofen has been shown to provide efficient analgesia and an opioid-sparing effect after orthopedic surgery. In this dose-finding study, we evaluated the analgesic efficacy and opioid-sparing effect of dexketoprofen administered intravenously (i.v.) after laparoscopic cholecystectomy (LCC).

Methods Twenty-four patients undergoing LCC were randomized to receive dexketoprofen 10 or $50 \mathrm{mg}$ i.v. $15 \mathrm{~min}$ before the end of the surgery. Subjects were provided with $0.2 \mathrm{mg} / \mathrm{kg}$ of oxycodone at anesthesia induction. In the recovery room, pain was assessed with an 11-point numerical rating scale (NRS; score of $0=$ no pain, score of $10=$ most severe pain) every $10 \mathrm{~min}$. When the NRS score was $\geq 3 / 10$ at rest or $\geq 5 / 10$ at wound compression, a plasma sample was taken for analysis of oxycodone [to determine the minimum effective concentration (MEC)], its metabolites, and dexketoprofen. After that, subjects were titrated with oxycodone 2 or $3 \mathrm{mg}$ i.v. every 10 min until the NRS score was $<3 / 10$ at rest and $<5 / 10$ at wound compression. At this point, a second plasma sample was taken for analysis of oxycodone
\end{abstract}

Merja Kokki

merja.kokki@kuh.fi

1 Anaesthesiology and Intensive Care Medicine, School of Medicine, University of Eastern Finland, Kuopio, Finland

2 Department of Anesthesia and Operative Services, Kuopio University Hospital, PO Box 100, 70029 Kuopio, Finland

3 School of Pharmacy, University of Eastern Finland, Kuopio, Finland

4 Department of Surgery, Kuopio University Hospital, Kuopio, Finland

5 Admescope Ltd, Oulu, Finland [minimum effective analgesic concentration (MEAC)], its metabolites, and dexketoprofen.

Results At the onset of pain, the plasma oxycodone concentrations (MEC) were similar in the two groups: median $60 \mathrm{ng} / \mathrm{mL}$ (range 37-73) in the $10 \mathrm{mg}$ group and median $52 \mathrm{ng} / \mathrm{mL}$ (range 24-79) in the $50 \mathrm{mg}$ group. At the time of pain relief, the MEACs were $98 \mathrm{ng} / \mathrm{mL}$ (range 59-150) in the $10 \mathrm{mg}$ group and $80 \mathrm{ng} / \mathrm{mL}$ (range $45-128$ ) in the $50 \mathrm{mg}$ group. The total doses of oxycodone needed to achieve pain relief were similar: $0.11 \mathrm{mg} / \mathrm{kg}$ (range $0-0.33$ ) in the $10 \mathrm{mg}$ group and $0.08 \mathrm{mg} / \mathrm{kg}$ (range $0-0.24$ ) in the $50 \mathrm{mg}$ group. Eleven subjects developed mild desaturation or a decreased respiratory rate after oxycodone titration.

Conclusion In the present double-blinded, randomized clinical trial, the need for a rescue opioid analgesic, oxycodone, was similar with the two dose levels of dexketoprofen-10 and $50 \mathrm{mg}$ i.v. - after LCC.

\section{Key Points}

Early pain after laparoscopic cholecystectomy is often severe, and most patients need an opioid analgesic.

Postoperative pain is multifactorial, but tissue trauma from the incision sites is the main origin of pain after laparoscopy.

Nonsteroidal anti-inflammatory analgesics are often highly effective in postoperative pain management, as surgery causes both pain and inflammation.

In the present study, the need for a rescue opioid analgesic, oxycodone, was similar with two dose levels of intravenous dexketoprofen-10 and $50 \mathrm{mg}$-after laparoscopic cholecystectomy. 


\section{Introduction}

Pain in the early phase of recovery after laparoscopic cholecystectomy (LCC) is often severe [1-3]. Intense acute pain is the main reason for prolonged recovery after LCC [4], and it may also predict development of chronic pain [1, 5-7]. In two studies, relatively high doses of opioids were needed for sufficient pain relief in patients undergoing LCC $[2,3]$. This is a concern because acute exposure to higher doses of opioids may result in long-lasting hyperalgesia [8]. Moreover, in acute pain management, the utility function for opioids is often negative, i.e. the analgesic opioid concentration could be even higher than that inducing adverse effects $[2,9]$. To prevent opioid-induced hyperalgesia and to reduce the total consumption of opioids in acute pain management, opioid analgesics are often combined with non-opioid analgesics, such as nonsteroidal anti-inflammatory drugs (NSAIDs). Coadministration of NSAIDs may reduce the risk of adverse effects of opioids. This has been shown with coadministration of ketoprofen with morphine: the decrease in ventilation was less pronounced when the NSAID was administered in conjunction with the opioid [10]. NSAIDs have a significant opioidsparing effect in postoperative pain management, which is most evident in patients undergoing orthopedic surgery [11] but is also evident in those undergoing gastrointestinal surgery [1]. In addition, recent evidence has indicated that in abdominal surgery, early postoperative use of NSAIDs may decrease postoperative complications [12].

Ketoprofen is one of the most extensively evaluated NSAIDs in postoperative pain management [13, 14]. Ketoprofen is a racemic compound. The $S(+)$-enantiomer, dexketoprofen, has analgesic activity, while the contribution of the $R(-)$-enantiomer to analgesic efficacy is minimal [15]. Dexketoprofen provides similar analgesic efficacy at half the dose of racemic ketoprofen and is thus likely to be better tolerated [13].

In our previous randomized clinical trial evaluating the effect of intravenous (i.v.) paracetamol 1 or $2 \mathrm{~g}$ on the need for postoperative rescue oxycodone after elective LCC, no difference between the two dose levels was found, and the total dose of oxycodone for sufficient analgesia was relatively high [3]. Early pain after surgery is both nociceptive and inflammatory, and experimental evidence indicates that traditional NSAIDs may decrease both nociceptive and inflammatory pain [16]. Thus, dexketoprofen may perform better than paracetamol in LCC patients. To test this, we designed the present randomized, double-blinded clinical trial, where our study hypothesis was that dexketoprofen would have dose-dependent opioidsparing efficacy in subjects undergoing LCC.

The main outcome measures were the minimum effective concentration (MEC) and the minimum effective analgesic concentration (MEAC) of oxycodone when it was coadministered with either 10 or $50 \mathrm{mg}$ of dexketoprofen i.v. in subjects undergoing elective LCC.

\section{Materials and methods}

The study was designed as a prospective, randomized, double-blinded clinical trial, with two parallel groups. The protocol was approved by the Research Ethics Committee of the Hospital District of Northern Savo, Kuopio, Finland (approval no. 41//2013; 29.7.2013), the Finnish Medicines Agency was notified of it (approval no. 71//2013; 10.7.2013), and the trial was registered in the EudraCT database (no. 2013-002085-39). The study was conducted in accordance with the Declaration of Helsinki.

\subsection{Participants}

A total of 26 patients scheduled for elective LCC at Kuopio University Hospital (Kuopio, Finland) in 2014 were asked to participate in this trial, and 24 of them agreed and gave their written informed consent for participation in the trial. The subjects included in the trial were 18-65 years old and had an American Society of Anesthesiologists physical status class of I-III. At enrolment, we excluded patients with a body mass index over $35 \mathrm{~kg} / \mathrm{m}^{2}$; sleep apnea or another disease affecting the respiratory center; renal, hepatic or pulmonary impairment; increased risk of bleeding; paralytic ileus or acute abdominal pain; previously diagnosed peptic ulcer or malignant disease; history of alcohol or narcotic abuse; or an allergy to any of the drugs or excipients used in the study; those who used monoamine oxidase inhibitors or opioids regularly; and those who were lactating or pregnant.

\subsection{Study Design}

The flow chart for the study is presented in Fig. 1. The operations were carried out by four consultant-level surgeons, and the same standardized surgical technique was used in both groups. The LCC procedure was performed using the four-trocar technique (one $10 \mathrm{~mm}$ and three $5 \mathrm{~mm}$ trocars). An optical trocar was used to penetrate into the abdominal cavity, and the intra-abdominal pressure was set at $12 \mathrm{mmHg}$.

The surgery was performed under standardized endotracheal anesthesia. Subjects were allowed to have diazepam $10 \mathrm{mg}$ by mouth as premedication if they were anxious. Anesthesia was induced with propofol, and a remifentanil infusion of $250-500 \mu \mathrm{g} / \mathrm{h}$ was used for intraoperative analgesia. For muscle relaxation, subjects were given rocuronium $0.6 \mathrm{mg} / \mathrm{kg}$ to achieve a deep 
Fig. 1 Flow chart. i.v. Intravenously, MEAC minimum effective analgesic concentration, $M E C$ minimum effective concentration, NRS numerical rating scale score

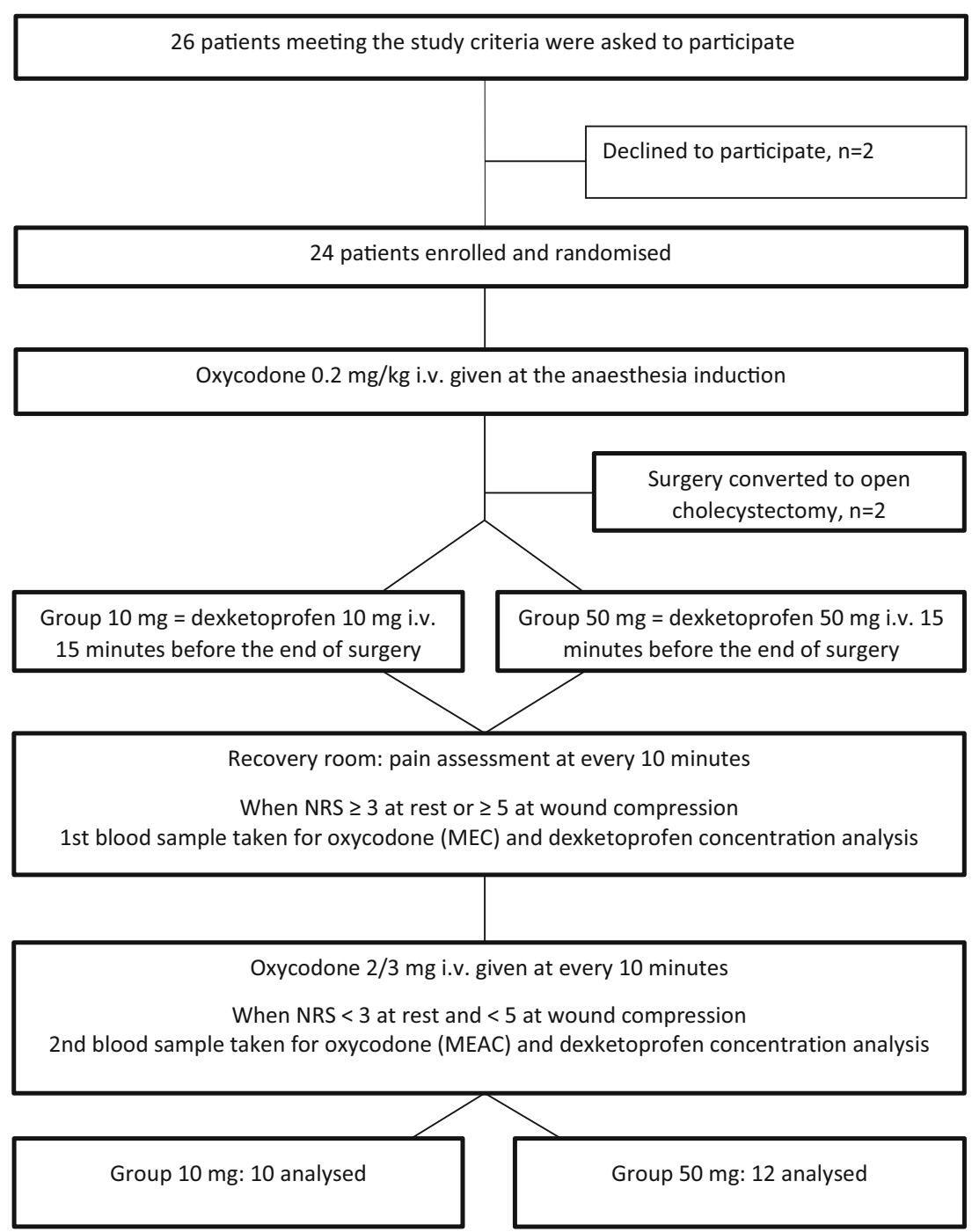

neuromuscular block with a post-tetanic count (PTC) of 2-5. If the PTC was higher than 5, the subject was given repetitive doses of rocuronium $0.1 \mathrm{mg} / \mathrm{kg}$ until the PTC was $\leq 5$. Anesthesia was maintained with desflurane in oxygen in air, and the desflurane inhalation was adjusted to maintain the state entropy values between 40 and 60 . Oxycodone $0.2 \mathrm{mg} / \mathrm{kg}$ (Oxanest $10 \mathrm{mg} / \mathrm{mL}$; Oy Leiras Takeda Pharmaceuticals AB, Helsinki, Finland) was given at anesthesia induction, and the Surgical Pleth Index (SPI) [Carescape $^{\mathrm{TM}}$ B650; GE Healthcare, Helsinki, Finland] was maintained at values between 20 and 50 by adjustment of the infusion rate of remifentanil.

The blood pressure, heart rate, peripheral oxygen saturation $\left(\mathrm{SpO}_{2}\right)$, end-tidal $\mathrm{CO}_{2}$ concentration $\left(\mathrm{etCO}_{2}\right)$, anesthesia gases, entropy, and SPI were monitored continuously with the Carescape ${ }^{\mathrm{TM}}$ B650. Neuromuscular monitoring was performed with acceleromyography (TOF-Watch SX; TOF-Watch SX Organon Ltd, Dublin, Ireland). The depth of neuromuscular blockade was controlled with train-of- four (TOF) and PTC stimulation. The monitoring data were collected to computer records, using Datex-Ohmeda ${ }^{\mathrm{TM}}$ S/5 Collect software (GE Healthcare, Helsinki, Finland).

Approximately $15 \mathrm{~min}$ before the end of surgery, subjects were given a 5 min i.v. injection of either dexketoprofen $10 \mathrm{mg}$ (in the $10 \mathrm{mg}$ group) or dexketoprofen $50 \mathrm{mg}$ (in the $50 \mathrm{mg}$ group) [Ketesse $50 \mathrm{mg} / 2 \mathrm{~mL}$; BerlinChemie/A. Menarini Suomi Oy, Helsinki, Finland], diluted in $20 \mathrm{~mL}$ of normal saline in a double-blinded manner. The randomization list was generated by computer (http://www. randomization.com), and a sealed envelope method was used for blinding. A hospital pharmacist prepared and concealed the random assignments from other persons involved in the study.

After the last skin suture, the remifentanil infusion and inhalation of desflurane were discontinued, and subjects were given sugammadex $2 \mathrm{mg} / \mathrm{kg}$ i.v. to reverse the neuromuscular block. Neuromuscular monitoring was continued until the TOF ratio was 0.9 or higher, and then the 
endotracheal tube was removed. The time from the sugammadex injection to a TOF ratio of $\geq 0.9$ was recorded.

At the start of the surgery, an indwelling catheter for blood sampling was placed in the cubital vein of the arm contralateral to the remifentanil infusion. No injections or infusions were given in that arm.

In the recovery room, pain intensity was assessed every $10 \mathrm{~min}$, using an 11-point numerical rating scale (NRS; score of $0=$ no pain, score of $10=$ most severe pain) at rest and during pressure on each of the wounds with a 20-Newton force $(2 \mathrm{~kg}$ of pressure with three fingers on a $10 \mathrm{~cm}^{2}$ area). The force of the wound compression was standardized by application of pressure on a kitchen scale (Soehnle, Nassau, Germany) before application to every patient and two or three times during each case [2,3]. When the pain at rest was $3 / 10$ or more, or the pain following wound compression was $5 / 10$ or more (the highest score of the four wounds), the first blood sample was taken (to determine the MEC). After this, the subjects received an i.v. oxycodone dose ( $2 \mathrm{mg}$ of oxycodone for bodyweight of $<80 \mathrm{~kg}$ or height of $<165 \mathrm{~cm}$, and $3 \mathrm{mg}$ of oxycodone for bodyweight of $\geq 80 \mathrm{~kg}$ and height of $\geq 165 \mathrm{~cm}$ ) every 10 min until the pain at rest was below $3 / 10$ and the pain after wound compression was below 5/10. The second blood sample was obtained for the MEAC of oxycodone $20 \mathrm{~min}$ after the last oxycodone dose-that is, when the subject had low pain scores at two consecutive assessments. The plasma oxycodone concentration obtained at the onset of significant pain was used as an estimate of the MEC, and the P-oxycodone concentration measured at the time of pain relief was used as an estimate of the MEAC of oxycodone with coadministration of dexketoprofen.

Blood samples were protected from light and centrifuged after sampling, and the plasma was divided into four polypropylene tubes. Samples were stored at $-72{ }^{\circ} \mathrm{C}$ until analysis.

In the recovery room, we also measured and recorded the arterial blood pressure, heart rate, $\mathrm{SpO}_{2}$, etCO $\mathrm{C}_{2}$, respiratory rate, sedation and adverse effects. Sedation was evaluated by using the Richmond Agitation-Sedation Scale (RASS; $-5=$ unarousable, no response to voice or physical stimulation; $+4=$ overly combative, violent, immediate danger to staff) [17].

During the study, no other pain medication or wound infiltrations were given to the subjects. All medications given were recorded. After the second blood sample was obtained, the study ended, and pain management was continued with the normal protocol of the hospital.

\subsection{Sample Analysis}

Plasma concentrations of oxycodone, noroxycodone, oxymorphone, and noroxymorphone were analyzed with a triple quadrupole mass spectrometer and ultra-performance liquid chromatography system (LC-MS/MS) method, as described earlier [18]. The concentrations of oxycodone, noroxycodone, oxymorphone, and noroxymorphone are reported as hydrochlorides. At the lower limit of quantification, the accuracy of the assay was $80-120 \%$ and the coefficient of variation $(\mathrm{CV})$ was below $20 \%$. The calibration ranges for the plasma samples were as follows: oxycodone $0.2-500 \mathrm{ng} / \mathrm{mL}$, noroxycodone $0.5-200 \mathrm{ng} / \mathrm{mL}$, oxymorphone $\quad 0.2-100 \mathrm{ng} / \mathrm{mL}$, and noroxymorphone $0.2-200 \mathrm{ng} / \mathrm{mL}$.

Dexketoprofen concentrations were analyzed by quantitative liquid chromatography with triple quadrupole mass spectrometric detection (LC-MS/MS), which was based on the methods described earlier by Gynther et al. [19]. Briefly, after plasma samples were thawed unassisted on top of ice, $100 \mu \mathrm{L}$ of plasma was extracted with $400 \mu \mathrm{L}$ of acetonitrile solution containing $0.1 \%$ formic acid and $100 \mathrm{ng} / \mathrm{mL}$ of $d 3$-ketoprofen as an internal standard. Samples were then vortex mixed and left to cool on top of ice. Cooled samples were centrifuged at $10,000 \mathrm{rpm}$ for $5 \mathrm{~min}$ at $10{ }^{\circ} \mathrm{C}$, the supernatants $(50 \mu \mathrm{L})$ were transferred to sample vials containing $50 \mu \mathrm{L}$ of water, and the tubes were briefly vortexed. Ketoprofen was quantified by liquid chromatography (using an Agilent 1290 Rapid Resolution LC System; Agilent Technologies, Waldbronn, Germany) coupled with an Agilent Jet Stream (AJS) ionization triple quadrupole mass spectrometer (Agilent 6495 Triple Quadrupole LC/MS; Agilent Technologies, Palo Alto, CA, USA). The injection volume was $5 \mu \mathrm{L}$, and the column used was a Zorbax Eclipse XDB-C18 Rapid Resolution HT $2.1 \times 50 \mathrm{~mm}, 1.8 \mu \mathrm{m}$ (Agilent Technologies, Palo Alto, CA, USA). The column temperature was $40{ }^{\circ} \mathrm{C}$, with a flow rate of $0.5 \mathrm{~mL} / \mathrm{min}$, and the gradient elution was used with water (eluent $\mathrm{A}$ ) and acetonitrile (eluent $\mathrm{B}$ ), both containing $0.1 \%(\mathrm{v} / \mathrm{v})$ of formic acid. The following gradient profile was employed: 0-2.5 min: $15 \rightarrow 95 \% \mathrm{~B}$; 2.5-4.5 min: $95 \% \mathrm{~B} ; \quad 4.5-4.51 \mathrm{~min}: \quad 95 \rightarrow 15 \% \mathrm{~B}$; 4.51-7.0 min: $15 \%$ B. The autosampler was maintained at $10{ }^{\circ} \mathrm{C}$. The following ionization conditions were used: positive ionization mode, drying gas (nitrogen) temperature $200{ }^{\circ} \mathrm{C}$, drying gas flow rate $16 \mathrm{~L} / \mathrm{min}$, nebulizer gas pressure $25 \mathrm{psi}$, sheath gas temperature $400{ }^{\circ} \mathrm{C}$, sheath gas flow $11 \mathrm{~L} / \mathrm{min}$, capillary voltage $4000 \mathrm{~V}$, and nozzle voltage $500 \mathrm{~V}$. The ion funnel parameters were as follows: high-pressure ion funnel RF voltage (HPRF) $200 \mathrm{~V}$ and low-pressure ion funnel RF voltage (LPRF) $100 \mathrm{~V}$. Analyte detection was performed using multiple reaction monitoring (MRM) with the following transitions (and collision energy values in parentheses): $\mathrm{m} / z 255 \rightarrow 209$ as the quantifier ion transition for ketoprofen [collision-induced dissociation (CID) $13 \mathrm{~V}], \mathrm{m} / z \quad 255 \rightarrow 105$ and $m / z 255 \rightarrow 77$ as the qualifier ion transitions for ketoprofen 
$($ CID 25 and $50 \mathrm{~V}$ ), and $\mathrm{m} / \mathrm{z} 258 \rightarrow 212$ for $d 3$-ketoprofen (internal standard, CID $13 \mathrm{~V}$ ). The dwell time was $75 \mathrm{~ms}$ for each transition, and the mass resolution value for the MS1 and MS2 quadrupoles was 0.7 full width at half maximum (FWHM) for both. The calibration range of the method was $13-5190 \mathrm{ng} / \mathrm{mL}$.

\subsection{Statistical Analysis}

A sample size calculation was based on our previous results, where the mean oxycodone MEC was $24 \mathrm{ng} / \mathrm{mL}$ with a standard deviation (SD) of $4.2 \mathrm{ng} / \mathrm{mL}$ [2]. In order to detect a $25 \%$ difference in the MEC between the two groups with a desired significance of 0.05 , a sample of 12 subjects in both groups was required to achieve a study power of 0.9 .

The data were entered and analyzed using Statistical Package for Social Science (SPSS) version 21.0 software (IBM, Chicago, IL, USA). The results are presented as individual values, median and range values, $95 \%$ confidence intervals (CIs), and means and SDs as appropriate. The interindividual CVs were calculated for both MEC and MEAC values. The differences between the two groups were compared using Mann-Whitney $U$ tests for continuous and ordinal variables, and for dichotomous data we used Pearson's Chi-squared tests. The correlations were compared, calculating Pearson correlation coefficients. A two-sided $p$ value of 0.05 was considered the limit of statistical significance.

\section{Results}

\subsection{Baseline Characteristics}

Twenty-four patients agreed to participate in the study, but in two subjects the surgery was converted to open cholecystectomy. The data from these two subjects were not included in the analysis. The remaining subjects' characteristics are presented in Table 1.

\subsection{Remifentanil Doses}

The median remifentanil doses were relatively small in both groups: $0.072 \mu \mathrm{g} / \mathrm{kg} / \mathrm{min}$ (range $0.034-0.13$ ) in the $10 \mathrm{mg}$ group and $0.078 \mu \mathrm{g} / \mathrm{kg} / \mathrm{min}$ (range $0.045-0.14$ ) in the $50 \mathrm{mg}$ group $(p=0.84)$.

\subsection{Oxycodone Consumption}

There was no difference between the two study groups in cumulative oxycodone consumption during the early phase of recovery after LCC. The median oxycodone doses were
$0.11 \mathrm{mg} / \mathrm{kg}$ (range $0.0-0.33$ ) in the $10 \mathrm{mg}$ group and $0.08 \mathrm{mg} / \mathrm{kg}$ (range $0.0-0.24$ ) in the $50 \mathrm{mg}$ group ( $p=0.28$ ) (Fig. 2). Three subjects developed only mild pain (NRS scores of $<3 / 10$ at rest and $<5 / 10$ at wound compression) during the first $2 \mathrm{~h}$ after surgery and therefore did not receive oxycodone for rescue analgesia: one subject in the $10 \mathrm{mg}$ group (subject no. 21) and two subjects in the $50 \mathrm{mg}$ group (subject nos. 6 and 8) (Table 2).

\subsection{Plasma Concentrations of Oxycodone and Its Metabolites}

Plasma oxycodone concentrations at the onset of pain (MEC) and at the time of pain relief (MEAC) were similar in the two groups (Table 2). The median P-oxycodone concentrations at pain onset were $60 \mathrm{ng} / \mathrm{mL}$ (range 37-73) in the $10 \mathrm{mg}$ group and $52 \mathrm{ng} / \mathrm{mL}$ (range 24-79) in the $50 \mathrm{mg}$ group (mean difference $4 \mathrm{ng} / \mathrm{mL}, 95 \% \mathrm{CI}-8$ to $17, p=0.63)$. At the time of pain relief, the median oxycodone concentrations were $98 \mathrm{ng} / \mathrm{mL}$ (range 59-150) in the $10 \mathrm{mg}$ group and $80 \mathrm{ng} / \mathrm{mL}$ (range 45-128) in the $50 \mathrm{mg}$ group (mean difference $18 \mathrm{ng} / \mathrm{mL}, 95 \% \mathrm{CI}-6$ to $44, p=0.18$ ). For MEC values, the interindividual $\mathrm{CV}$ was $26 \%$, and for MEAC values it was $30 \%$.

No difference in the median concentrations of oxycodone metabolites were found between the two groups. Plasma concentrations of the active metabolite oxymorphone were low, and the inactive metabolite noroxycodone was the main metabolite detected at both times (Table 3).

\subsection{Plasma Concentrations of Dexketoprofen}

The median dexketoprofen doses were $0.12 \mathrm{mg} / \mathrm{kg}$ (range $0.11-0.17$ ) in the $10 \mathrm{mg}$ group and $0.66 \mathrm{mg} / \mathrm{kg}$ (range $0.45-0.83)$ in the $50 \mathrm{mg}$ group. The dexketoprofen dose did not correlate with the MEC $(r=-0.17, p=0.45)$ or with the MEAC ( $r=-0.31, p=0.2$; Pearson correlation coefficient).

At pain onset, the mean P-dexketoprofen concentration was higher in the $50 \mathrm{mg}$ group [4517 ng/mL (range 801-7580)] than in the $10 \mathrm{mg}$ group [564 $\mathrm{ng} / \mathrm{mL}$ (range 116-1594)], as expected. This was also the case at the time of pain relief: the mean P-dexketoprofen concentrations were $1502 \mathrm{ng} / \mathrm{mL}$ (range 607-2647) in the $50 \mathrm{mg}$ group and $232 \mathrm{ng} / \mathrm{mL}$ (range 109-477) in the $10 \mathrm{mg}$ group.

\subsection{Rocuronium Doses}

The median total doses of rocuronium given during the surgery were $80 \mathrm{mg}$ (range 70-190) in the $10 \mathrm{mg}$ group and $92 \mathrm{mg}$ (range 50-125) in the $50 \mathrm{mg}$ group. The median time from administration of sugammadex to recovery of a TOF ratio $\geq 0.9$ was $1 \mathrm{~min} 50 \mathrm{~s}$ (range $1-5 \mathrm{~min} 30 \mathrm{~s}$ ) in the 
Table 1 Patient characteristics

\begin{tabular}{llc}
\hline Variable & Value, mean (SD) [range] & \\
\cline { 2 - 3 } & $10 \mathrm{mg}$ dexketoprofen group $(n=10)$ & 50 mg dexketoprofen group $(n=12)$ \\
\hline Age (years) & $50(9.88)[27-59]$ & $52(10.4)[33-65]$ \\
Weight $(\mathrm{kg})$ & $80(12)[60-93]$ & $79(15)[60-112]$ \\
Height $(\mathrm{m})$ & $1.69(0.11)[1.57-1.89]$ & $1.66(0.10)[1.54-1.83]$ \\
BMI $\left(\mathrm{kg} / \mathrm{m}^{2}\right)$ & $27.9(4.0)[21.0-45.7]$ & $28.5(3.76)[20.6-46.6]$ \\
Duration of anesthesia (h:min) & $1: 43(0: 24)[1: 02-2: 25]$ & $1: 45(0: 26)[1: 00-2: 45]$ \\
Duration of surgery (h:min) & $1: 09(0: 23)[0: 29-1: 55]$ & $1: 06(0: 23)[0: 27-2: 00]$ \\
\hline
\end{tabular}

$B M I$ body mass index, $S D$ standard deviation

Fig. 2 Mean oxycodone consumption in the 2 dose groups during the first 2 postoperative hours, expressed as the cumulative oxycodone dose $(\mathrm{mg})$ and the number of bolus doses

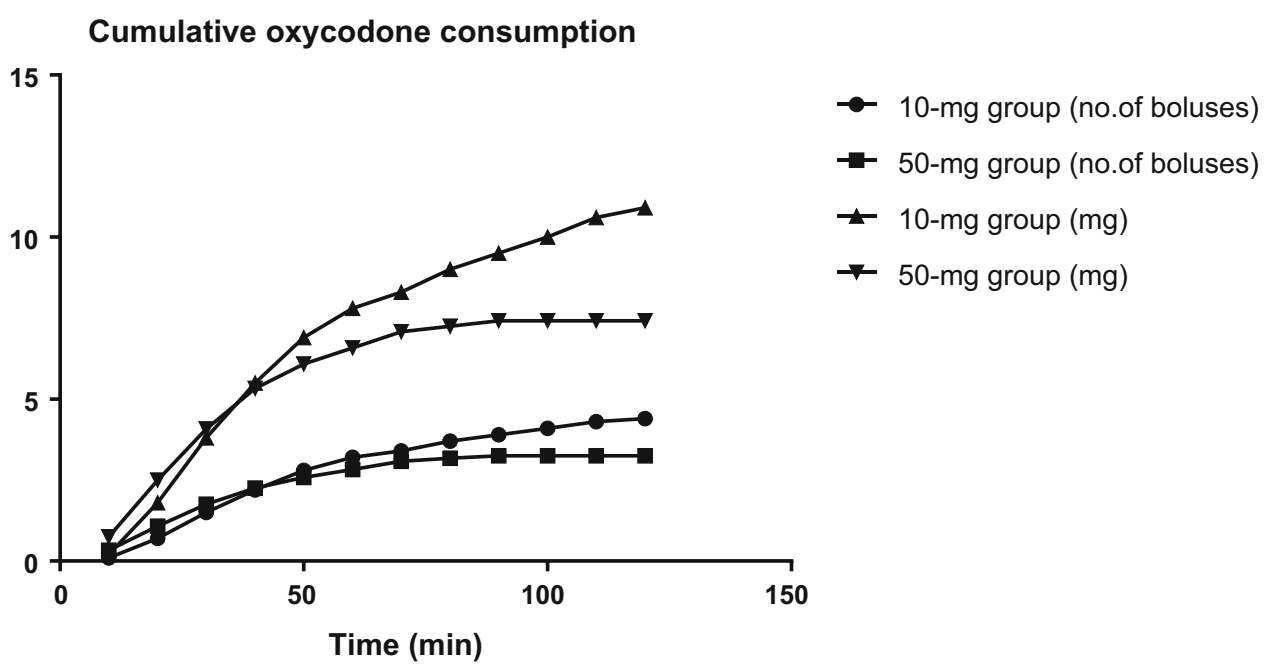

$10 \mathrm{mg}$ group and $2 \mathrm{~min} 50 \mathrm{~s}$ (range $1 \mathrm{~min} 8 \mathrm{~s}$ to $5 \mathrm{~min}$ $10 \mathrm{~s}$ ) in the $50 \mathrm{mg}$ group.

\subsection{Onset of Pain}

No difference was found in the time from the end of anesthesia to the onset of pain. The median times were $26 \mathrm{~min}$ (from $10 \mathrm{~min}$ to $1 \mathrm{~h} 10 \mathrm{~min}$ ] in the $10 \mathrm{mg}$ group and $21 \mathrm{~min}$ (from $8 \mathrm{~min}$ to $42 \mathrm{~min}$ ) in the $50 \mathrm{mg}$ group, respectively $(p=0.32)$.

\subsection{Haemodynamic and Respiratory Parameters}

The arterial blood pressure, heart rate, $\mathrm{SpO}_{2}$, etCO $\mathrm{O}_{2}$ and respiratory rate values were similar in the two groups (Fig. 3). However, the number of patients with transient episodes of respiratory depression was smaller in the $50 \mathrm{mg}$ group than in the $10 \mathrm{mg}$ group (see below).

\subsection{Adverse Effects}

There were no unexpected or severe adverse effects during the study. The adverse effects observed were all considered to be related to study medications. A total of 15 subjects developed 29 adverse effects. In the $10 \mathrm{mg}$ group, one subject had four, two subjects had three, three subjects had two, and one subject had one adverse effect $\left(\mathrm{SpO}_{2}<94 \%\right.$, $n=6$; respiratory rate $<10$ breaths/min, $n=4$; nausea, $n=4$; pruritus, $n=2$; shivering, $n=2$ ). In the $50 \mathrm{mg}$ group, three subjects had two adverse effects and four subjects had one adverse effect $\left(\mathrm{SpO}_{2}<94 \%, n=3\right.$; respiratory rate $<10$ breaths/min, $n=2$; nausea, $n=5$ ). Seven of ten subjects in the $10 \mathrm{mg}$ group and four of 12 subjects in the $50 \mathrm{mg}$ group had either low $\mathrm{SpO}_{2}$ or a low respiratory rate $(p=0.087)$.

\section{Discussion}

In the present dose-finding study, there was no difference in the analgesic efficacy of dexketoprofen at doses of 10 and $50 \mathrm{mg}$ i.v. in early-phase pain management after LCC. The cumulative oxycodone consumption, the time to the need for rescue analgesia, and the MEC and MEAC values were similar in the two groups. This was not expected, because in our earlier study in children 
Table 2 Individual patient characteristics and oxycodone plasma concentrations

\begin{tabular}{|c|c|c|c|c|c|c|c|c|}
\hline $\begin{array}{l}\text { Patient } \\
\text { no. }\end{array}$ & Sex & $\begin{array}{l}\text { Age } \\
\text { (year)s }\end{array}$ & $\begin{array}{l}\text { Weight } \\
(\mathrm{kg})\end{array}$ & $\begin{array}{l}\text { Height } \\
\text { (m) }\end{array}$ & $\begin{array}{l}\text { P-oxycodone } \\
\text { concentration at pain } \\
\text { onset }(\mathrm{ng} / \mathrm{mL})\end{array}$ & $\begin{array}{l}\text { Time of pain } \\
\text { onset after } \\
\text { surgery (min) }\end{array}$ & $\begin{array}{l}\text { Oxycodone } \\
\text { consumption, no. of } \\
\text { bolus doses (mg) }\end{array}$ & $\begin{array}{l}\text { P-oxycodone } \\
\text { concentration at time of } \\
\text { pain relief }(\mathrm{ng} / \mathrm{mL})\end{array}$ \\
\hline \multicolumn{9}{|c|}{ Dexketoprofen $10 \mathrm{mg}$ group } \\
\hline 2 & Female & 57 & 93 & 1.66 & 73.4 & 27 & $2(6)$ & 98.2 \\
\hline 3 & Female & 53 & 66 & 1.60 & 54.2 & 30 & $4(8)$ & 93.7 \\
\hline 7 & Female & 39 & 90 & 1.67 & 64.8 & 21 & $10(30)$ & 150.0 \\
\hline 9 & Male & 51 & 83 & 1.83 & 65.5 & 21 & $4(12)$ & 113.0 \\
\hline 10 & Male & 55 & 77 & 1.75 & 62.4 & 26 & $7(14)$ & 99.3 \\
\hline 11 & Male & 54 & 84 & 1.72 & 57.9 & 110 & $2(6)$ & 81.0 \\
\hline 12 & Male & 27 & 92 & 1.89 & 69.6 & 23 & $3(9)$ & 86.0 \\
\hline 21 & Female & 55 & 88 & 1.60 & 36.9 & 140 & $0(0)$ & - \\
\hline 22 & Female & 45 & 65 & 1.62 & 44.0 & 50 & $3(6)$ & 58.6 \\
\hline 23 & Female & 59 & 60 & 1.57 & 39.1 & 10 & $9(18)$ & 109.0 \\
\hline \multicolumn{9}{|c|}{ Dexketoprofen $50 \mathrm{mg}$ group } \\
\hline 1 & Female & 59 & 78 & 1.54 & 59.4 & 42 & $2(4)$ & 69.5 \\
\hline 4 & Female & 57 & 70 & 1.58 & 54.2 & 8 & $2(4)$ & 89.2 \\
\hline 6 & Male & 65 & 85 & 1.72 & 59.2 & 132 & $0(0)$ & - \\
\hline 8 & Female & 58 & 61 & 1.58 & 39.2 & 136 & $0(0)$ & - \\
\hline 13 & Male & 41 & 112 & 1.83 & 65.5 & 15 & $4(12)$ & 100.0 \\
\hline 14 & Female & 58 & 73 & 1.61 & 71.1 & 17 & 7 (14) & 128.0 \\
\hline 15 & Female & 56 & 65 & 1.67 & 79.3 & 24 & $2(4)$ & 98.5 \\
\hline 16 & Female & 54 & 88 & 1.60 & 24.3 & 40 & $3(9)$ & 45.8 \\
\hline 17 & Male & 61 & 95 & 1.81 & 48.7 & 17 & $2(6)$ & 63.8 \\
\hline 18 & Female & 35 & 87 & 1.69 & 44.4 & 32 & $1(3)$ & 45.4 \\
\hline 20 & Female & 51 & 60 & 1.57 & 42.4 & 25 & $6(12)$ & 71.3 \\
\hline 24 & Female & 33 & 74 & 1.72 & 41.6 & 10 & 9 (18) & 88.1 \\
\hline
\end{tabular}

Table 3 Concentrations of the metabolites of oxycodone

\begin{tabular}{|c|c|c|c|c|c|c|}
\hline & \multicolumn{3}{|c|}{ Metabolite concentration at pain onset $(\mathrm{ng} / \mathrm{mL})$} & \multicolumn{3}{|c|}{ Metabolite concentration at time of pain relief $(\mathrm{ng} / \mathrm{mL})$} \\
\hline & P-noroxymorphone & P-noroxycodone & P-oxymorphone & P-noroxymorphone & P-noroxycodone & P-oxymorphone \\
\hline \multicolumn{7}{|c|}{ Dexketoprofen $10 \mathrm{mg}$ group } \\
\hline $\begin{array}{l}\text { Mean (SD) } \\
\text { [range] }\end{array}$ & $1.3(0.4)[0.8-2.2]$ & $6.4(1.9)$ [4.3-10.7] & $0.5(0.2)[0.3-0.8]$ & $2.3(1.0)[1.0-3.6]$ & $11.5(3.9)[6.0-18.3]$ & $0.7(0.4)[0.4-1.4]$ \\
\hline \multicolumn{7}{|c|}{ Dexketoprofen $50 \mathrm{mg}$ group } \\
\hline $\begin{array}{l}\text { Mean (SD) } \\
\text { [range] }\end{array}$ & $1.3(0.4)[0.7-1.7]$ & $8.1(4.4)$ [4.6-20.5] & $0.4(0.2)[0.1-0.8]$ & $2.1(0.5)$ [1.3-2.9] & $14.0(9.3)[5.5-34.0]$ & $0.5(0.2)[0.03-0.8]$ \\
\hline
\end{tabular}

$S D$ standard deviation

undergoing adenoidectomy, dose-dependent opioid-sparing efficacy was found for racemic ketoprofen [20]. In that study, significant analgesic efficacy was demonstrated at a ketoprofen dose of $0.3 \mathrm{mg} / \mathrm{kg}$ i.v., and pain scores were lower and the need for rescue opioid analgesic was dosedependently lesser with higher doses of ketoprofen 1 and $3 \mathrm{mg} / \mathrm{kg}$ i.v., respectively. In the present study, the need for rescue opioids was one-third lesser in subjects receiving $50 \mathrm{mg}$ dexketoprofen i.v. than in subjects receiving $10 \mathrm{mg}$ dexketoprofen, but because of high interindividual variations in analgesic requests, the difference between the two groups was not significant.

In the present study, dexketoprofen was administered at the end of surgery, in contrast to the adenoidectomy study 
Fig. 3 a Mean haemodynamic parameters and $\mathbf{b}$ respiratory parameters in the 2 groups during the first 2 postoperative hours. DAP diastolic arterial blood pressure $(\mathrm{mmHg})$, et $\mathrm{CO}_{2}$ end-tidal carbon dioxide concentration (\%), HR heart rate (beats $/ \mathrm{min}), R R$ respiratory rate (breaths/min), SAP systolic arterial blood pressure $(\mathrm{mmHg})$ $\mathrm{SpO}_{2}$ peripheral oxygen saturation $(\%)$
Hemodynamic values

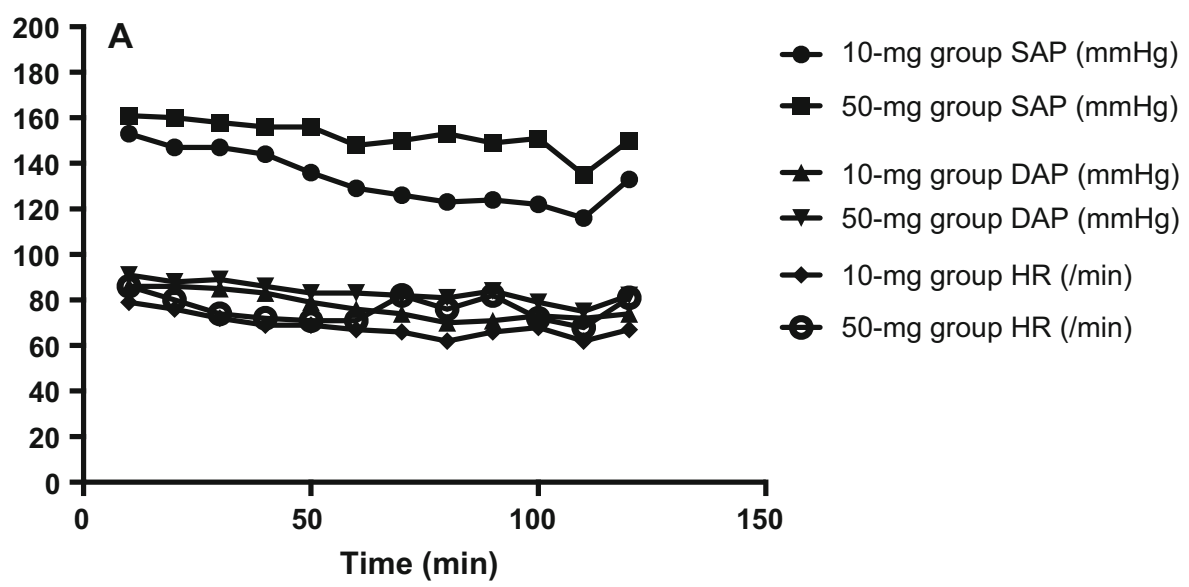

Respiratory values

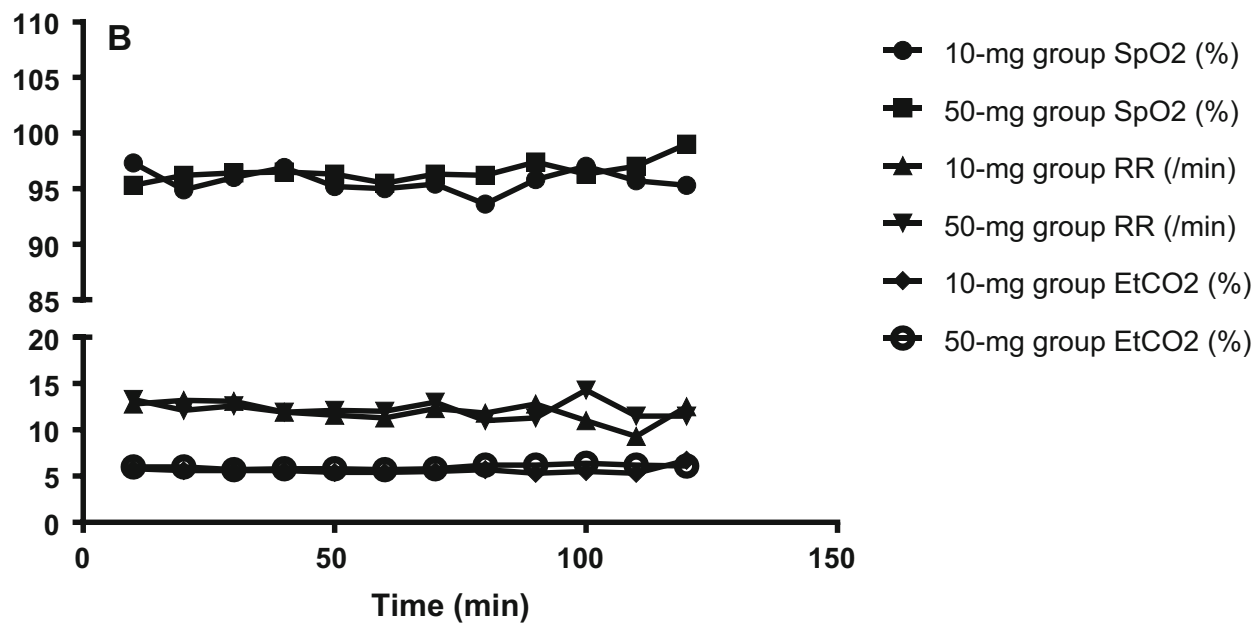

[20], in which ketoprofen was given during induction of anesthesia. This late administration may explain the lack of dose-dependent efficacy of dexketoprofen in the present study. The optimal timing of NSAID administration in surgical patients has not been established. In an earlier study in patients undergoing LCC, racemic ketoprofen $100 \mathrm{mg}$ i.v. given before induction of anesthesia was superior to the same dose given after surgery in the recovery room when each patient initially complained of pain [21]. Conversely, in tonsillectomy patients, preoperative ketoprofen did not perform better than the same dose at the end of surgery but before pain had been established [22]. NSAIDs have both peripheral and central nervous system analgesic actions. Ketoprofen penetrates readily into the central nervous system [23]. However, it may take up to $3 \mathrm{~h}$ before maximum concentrations are achieved in cerebrospinal fluid [24]. On the basis of their modes of action and pharmacokinetic characteristics, NSAIDs are more effective in prevention of acute pain than in relief of established pain.

Cholecystectomy is associated with perioperative bleeding complications in 1-2\% of cases [25]. Since NSAIDs inhibit platelet function, the first NSAID dose is often given only after primary hemostasis has developed [26]. In addition, there appears to be sufficient evidence to conclude that both renal function and renal blood flow decrease during pneumoperitoneum [27]. In settings of prolonged renal vasoconstriction, prostaglandins act to preserve renal blood flow and the glomerular filtration rate. Thus, preoperative use of NSAIDs may increase the risks of renal ischemia and acute kidney injury by blocking formation of prostaglandins [28]. Therefore, NSAID administration only at the end of pneumoperitoneum is preferable to preoperative administration.

Ketoprofen is a chiral molecule, and dexketoprofen, the $(S)$-enantiomer, is believed to confer analgesia. 
Theoretically, dexketoprofen is expected to provide analgesia equivalent to that provided by ketoprofen, but at half the dose [23]. High analgesic efficacy of dexketoprofen has been demonstrated-for example, in major orthopedic surgery and dental surgery $[11,29]$. Also, after lumbar disc surgery, dexketoprofen $50 \mathrm{mg}$ i.v. was superior to paracetamol $1 \mathrm{~g}$ i.v. [30]. The data from the present study indicate that dexketoprofen may have had significant analgesic efficacy after LCC. Cumulative oxycodone consumption for rescue analgesia was one-third lesser than in a similar study setting in which LCC patients were given paracetamol 1 or $2 \mathrm{~g}$ i.v. Also, three of the 22 subjects in the present study did not need rescue opioid analgesia after surgery, whereas all patients in the paracetamol study needed rescue oxycodone during the first hours after LCC [3]. However, as the loading dose during surgery was higher in the present study, the MEC and MEAC values were higher in the present study (50-60 and 80-90 ng/mL, respectively) than those in the paracetamol study (20-30 and 60-70 $\mathrm{ng} / \mathrm{mL}$, respectively).

In the present study, dexketoprofen was well tolerated, and no dexketoprofen-related adverse effects were recorded. However, for oxycodone, the utility function was found to be negative, since a total of 11 subjects developed signs of mild respiratory depression (a low respiratory rate and/or low $\mathrm{SpO}_{2}$ ) while still reporting moderate wound pain. These respiratory events were not associated with hypercapnia: a single etCO $\mathrm{CO}_{2}$ value of $7.0 \%$ was recorded; otherwise the etCO $\mathrm{O}_{2}$ values were between 4.5 and $6.4 \%$.

The main limitation of the present study was that we did not include a placebo group. Comparison with our previous results does indicate that dexketoprofen may have significant analgesic efficacy after LCC. However, there were a few differences between the study protocols, which may have had confounding effects. Another limitation was the relatively small number of included subjects. In the present study, the need for rescue opioid was one-third lesser in subjects receiving $50 \mathrm{mg}$ dexketoprofen i.v. than in those receiving $10 \mathrm{mg}$ dexketoprofen, but because of high interindividual variations in analgesic requests, the difference between the two groups was not significant. A study power calculation indicated that, with these numbers, 66 subjects per group would have needed to be enrolled to be able to show a statistically significant difference between the two groups.

The pain after laparoscopy is multifactorial and has multiple causes. In the early phase of recovery, patients may develop superficial and deep nociceptive somatic pain, visceral pain arising from the abdominal organs, neuropathic pain, and inflammatory pain in response to tissue trauma. Often the tissue trauma from the incision sites is the main origin of pain after laparoscopy. Thus, pain management after laparoscopy should reflect the large variation of pain manifestations. NSAIDs are useful for postoperative pain management, given that surgery causes both pain and inflammation. However, to treat severe pain, NSAIDs should be given as part of a multimodal approach.

\section{Conclusion}

Our results imply that similar analgesic efficacy could be achieved with a lower dose of dexketoprofen $(10 \mathrm{mg}$ i.v.) instead of the commonly used dose of $50 \mathrm{mg}$ i.v. However, opioid-induced respiratory depression was less significant with coadministration of the higher dose of dexketoprofen. More studies are needed to confirm the present results.

\section{Compliance with Ethical Standards}

This study was financially supported by the governmental VTR Fund, the Hospital District of Northern Savo, Kuopio, Finland.

The authors (Annika Piirainen, Hannu Kokki, Satu Immonen, Matti Eskelinen, Merja R. Häkkinen, Heidi Hautajärvi and Merja Kokki) have no conflicts of interest to declare.

Open Access This article is distributed under the terms of the Creative Commons Attribution-NonCommercial 4.0 International License (http://creativecommons.org/licenses/by-nc/4.0/), which permits any noncommercial use, distribution, and reproduction in any medium, provided you give appropriate credit to the original author(s) and the source, provide a link to the Creative Commons license, and indicate if changes were made.

\section{References}

1. Bisgaard T. Analgesic treatment after laparoscopic cholecystectomy: a critical assessment of the evidence. Anesthesiology. 2006;104:835-46.

2. Kokki M, Broms S, Eskelinen M, Rasanen I, Ojanpera I, Kokki H. Analgesic concentrations of oxycodone-a prospective clinical PK/PD study in patients with laparoscopic cholecystectomy. Basic Clin Pharmacol Toxicol. 2012;110:469-75.

3. Kokki M, Broms S, Eskelinen M, Neuvonen PJ, Halonen T, Kokki H. The analgesic concentration of oxycodone with coadministration of paracetamol-a dose-finding study in adult patients undergoing laparoscopic cholecystectomy. Basic Clin Pharmacol Toxicol. 2012;111:391-5.

4. Gurusamy KS, Vaughan J, Toon CD, Davidson BR. Pharmacological interventions for prevention or treatment of postoperative pain in people undergoing laparoscopic cholecystectomy. Cochrane Database Syst Rev. 2014;3:CD008261.

5. Aspinen S, Harju J, Juvonen P, Kokki H, Remes V, Scheinin T, et al. A prospective, randomized multicenter study comparing conventional laparoscopic cholecystectomy versus minilaparotomy cholecystectomy with ultrasonic dissection as day surgery procedure-1-year outcome. Scand J Gastroenterol. 2014;49:1336-42.

6. Aspinen S, Harju J, Juvonen P, Karjalainen K, Kokki H, Paajanen $\mathrm{H}$, et al. A prospective, randomized study comparing minilaparotomy and laparoscopic cholecystectomy as a day-surgery procedure: 5-year outcome. Surg Endosc. 2014;28:827-32.

7. Harju J, Aspinen S, Juvonen P, Kokki H, Eskelinen M. Ten-year outcome after minilaparotomy versus laparoscopic 
cholecystectomy: a prospective randomised trial. Surg Endosc. 2013;27:2512-6.

8. Heinl C, Drdla-Schutting R, Xanthos DN, Sandkuhler J. Distinct mechanisms underlying pronociceptive effects of opioids. J Neurosci. 2011;31:16748-56.

9. Boom M, Olofsen E, Neukirchen M, Fussen R, Hay J, Groeneveld GJ, et al. Fentanyl utility function: a risk-benefit composite of pain relief and breathing responses. Anesthesiology. 2013;119:663-74.

10. Moren J, Francois T, Blanloeil Y, Pinaud M. The effects of a nonsteroidal antiinflammatory drug (ketoprofen) on morphine respiratory depression: a double-blind, randomized study in volunteers. Anesth Analg. 1997;85:400-5.

11. Hanna MH, Elliott KM, Stuart-Taylor ME, Roberts DR, Buggy D, Arthurs GJ. Comparative study of analgesic efficacy and morphine-sparing effect of intramuscular dexketoprofen trometamol with ketoprofen or placebo after major orthopaedic surgery. Br J Clin Pharmacol. 2003;55:126-33.

12. STARSurg Collaborative. Impact of postoperative non-steroidal anti-inflammatory drugs on adverse events after gastrointestinal surgery. Br J Surg. 2014;101:1413-23.

13. Barden J, Derry S, McQuay HJ, Moore RA. Single dose oral ketoprofen and dexketoprofen for acute postoperative pain in adults. Cochrane Database Syst Rev. 2009;4:CD007355.

14. Sjövall S, Kokki M, Nokela A, Halinen L, Turunen M, Kokki H. Intravenous dexketoprofen induces less injection pain than racemic ketoprofen. J Clin Pharm Ther. 2015;40(4):431-5.

15. Barbanoj MJ, Antonijoan RM, Gich I. Clinical pharmacokinetics of dexketoprofen. Clin Pharmacokinet. 2001;40:245-62.

16. Zhu X, Conklin DR, Eisenach JC. Preoperative inhibition of cyclooxygenase- 1 in the spinal cord reduces postoperative pain. Anesth Analg. 2005;100:1390-3.

17. Sessler CN, Gosnell MS, Grap MJ, Brophy GM, O'Neal PV, Keane KA, et al. The Richmond Agitation-Sedation Scale: validity and reliability in adult intensive care unit patients. Am J Respir Crit Care Med. 2002;166:1338-44.

18. Kokki M, Valitalo P, Kuusisto M, Ranta VP, Raatikainen K, Hautajarvi $\mathrm{H}$, et al. Central nervous system penetration of oxycodone after intravenous and epidural administration. $\mathrm{Br} \mathrm{J}$ Anaesth. 2014;112:133-40.
19. Gynther M, Jalkanen A, Lehtonen M, Forsberg M, Laine K, Ropponen J, et al. Brain uptake of ketoprofen-lysine prodrug in rats. Int J Pharm. 2010;399:121-8.

20. Kokki H, Nikanne E, Tuovinen K. I.v. intraoperative ketoprofen in small children during adenoidectomy: a dose-finding study. $\mathrm{Br}$ J Anaesth. 1998;81:870-4.

21. Boccara G, Chaumeron A, Pouzeratte Y, Mann C. The preoperative administration of ketoprofen improves analgesia after laparoscopic cholecystectomy in comparison with propacetamol or postoperative ketoprofen. Br J Anaesth. 2005;94:347-51.

22. Salonen A, Kokki H, Tuovinen K. I.v. ketoprofen for analgesia after tonsillectomy: comparison of pre- and post-operative administration. Br J Anaesth. 2001;86:377-81.

23. Kokki H. Ketoprofen pharmacokinetics, efficacy, and tolerability in pediatric patients. Paediatr Drugs. 2010;12:313-29.

24. Netter P, Lapicque F, Bannwarth B, Tamisier JN, Thomas P, Royer RJ. Diffusion of intramuscular ketoprofen into the cerebrospinal fluid. Eur J Clin Pharmacol. 1985;29:319-21.

25. Trastulli S, Cirocchi R, Desiderio J, Guarino S, Santoro A, Parisi A, et al. Systematic review and meta-analysis of randomized clinical trials comparing single-incision versus conventional laparoscopic cholecystectomy. Br J Surg. 2013;100:191-208.

26. Li W, Lian YY, Yue WJ, Yang Q, Yue Q, Meng QG, et al. Experimental study of COX-2 selective and traditional nonsteroidal anti-inflammatory drugs in total hip replacement. J Int Med Res. 2009;37:472-8.

27. Demyttenaere S, Feldman LS, Fried GM. Effect of pneumoperitoneum on renal perfusion and function: a systematic review. Surg Endosc. 2007;21:152-60.

28. Whelton A. Nephrotoxicity of nonsteroidal anti-inflammatory drugs: physiologic foundations and clinical implications. Am J Med. 1999; 106:13S-24S.

29. Jackson ID, Heidemann BH, Wilson J, Power I, Brown RD. Double-blind, randomized, placebo-controlled trial comparing rofecoxib with dexketoprofen trometamol in surgical dentistry. Br J Anaesth. 2004;92:675-80.

30. Tunali Y, Akcil EF, Dilmen OK, Tutuncu AC, Koksal GM, Akbas S, et al. Efficacy of intravenous paracetamol and dexketoprofen on postoperative pain and morphine consumption after a lumbar disk surgery. J Neurosurg Anesthesiol. 2013;25:143-7. 